\title{
A construção de uma metodologia observacional para o estudo de crianças em situação de rua: criando um manual de codificação de atividades cotidianas ${ }^{l}$
}

\author{
Paola Biasoli Alves \\ Sílvia Helena Koller \\ Aline S. Silva \\ Caroline T. Reppold \\ Clarisse L. Santos \\ Gabriela S. Bichinho \\ Luciano T. Prade \\ Milena R. Silva \\ Universidade Federal do Rio Grande do Sul \\ Jonathan Tudge \\ University of North Carolina at Greensboro
}

Resumo

Este estudo teve por objetivo descrever uma metodologia criada para a observação de crianças em situação de rua em seu ambiente natural. Questões sobre o desenvolvimento dessas crianças, sobre a utilização e significado do espaço da rua e sobre os aspectos metodológicos foram relevantes para a realização deste tipo de estudo. Os resultados encon- 
tram-se condensados em um manual criado especialmente para a codificação das atividades cotidianas apresentadas pelas crianças em situação de rua. A discussão enfatiza a importância da realização de estudos observacionais exploratórios e descritivos para avaliar o processo de criação de metodologias específicas para entender e analisar o desenvolvimento humano em situações de risco. A aplicabilidade deste método é discutida como conhecimento produzido pela Psicologia do Desenvolvimento.

Palavras-chave: Crianças em situação de rua, observação naturalística, abordagem ecológica do desenvolvimento humano.
Key words: Children in street situation, natural observation, ecological approach.

\section{Abstract}

The construction of an observational method of studying children in the context of the street: creating a manual to codify daily activities

This study aims to describe a method created to observe children of the street in their natural environment. The development of these children, the meaning and the utilization of street space, and methodological aspects were considered. The results are presented in a manual elaborated to codify the daily activities of the observed children. The discussion emphasizes that observational, exploratory and descriptive studies are essential to validate the process of creative specific methodologies to understand and analyze human development at risk situations. In addition, the study shows the applicability of the method for a resulting knowledge to the field of developmental psychology. 
dessas crianças, quando comparadas com outras da mesma idade, apresenta alguma defasagem no desenvolvimento, seja em termos físicos, cognitivos ou sócio-emocionais (Alves, 1998; Hawkins, 1986; Hutz \& Koller, 1997) refletindo situações estressoras associadas à presença da miséria econômica e afetiva de alguns ambientes (Hutz \& Koller, 1997). Nesse sentido, é importante considerar as conseqüências do desemprego, da ausência de condições básicas de saúde e educação, de práticas educativas que promovem supersocialização ou subsocialização, além da ausência de apego seguro, abusos, exploração e das mais variadas formas de violência (Alves, 1998; Biasoli-Alves, 1992; Hutz \& Koller, 1997).

Dentro desse quadro geral de risco, a situação de rua consiste em um modelo específico, em que as crianças e adolescentes são caracterizados, principalmente, por sua presença, durante um ou mais períodos do dia, nas ruas (geralmente as ruas centrais das cidades, onde o comércio é a atividade mais freqüente). Eles se utilizam do espaço da rua para a realização de atividades humildes, como vender objetos (bilhetes lotéricos, plantas, santinhos etc.), engraxar sapatos ou mesmo pedir dinheiro e/ou comida. Em geral, aparecem sozinhas ou em grupos de pares que possuem a mesma característica, sem um adulto cuidador imediatamente identificável, aspecto que se associa à sua aparência de abandono (Alves, 1998; Brito, 1999; Forster, Barros, Tannhauser \& Tannhauser, 1992).

O objetivo deste estudo é apresentar a construção de uma metodologia de observação para coleta de dados com crianças em situação de rua e o modelo para sua análise, com base teóricometodológica na Abordagem Ecológica do Desenvolvimento Humano (Bronfenbrenner, 1979/1996, 1989, 1993). A rua é considerada um espaço no qual interagem fatores de risco e aspectos saudáveis dessas crianças, caracterizando-se como um ambiente de desenvolvimento. A observação do espaço da rua e da forma como as crianças o utilizam em suas atividades cotidianas permite um olhar descritivo da sua realidade. Diferentes categorias de comportamentos podem ser identificadas, desde atividades tipicamente infantis (brinquedo, interação com diversos parceiros, observação do ambiente e 
exercício motor), até atividades de trabalho relacionadas à sobrevivência e cuidado com a própria segurança. A observação naturalística dos comportamentos apresentados pelas crianças põe em discussão alguns aspectos da Psicologia do Desenvolvimento Humano. Salienta-se, então, a necessidade de estudos nesta área, nos quais o desenvolvimento dessas crianças seja analisado através das suas relações com o mundo infantil e adulto, e a vivência no espaço da rua.

A rua é um ambiente de múltiplas possibilidades. Para seu estudo e compreensão é necessário, inicialmente, que o pesquisador esteja disposto a observar e descrever sua dinâmica, utilizando-se, para tal, de metodologias que garantam o rigor dos achados (Bemak, 1996; Hutz \& Koller, 1999). Na rua convivem diferentes faixas etárias, as atividades realizadas envolvem dinheiro, diversão, alimentação e lazer, além de possibilidades de transgressão explícita, como o uso e o tráfico de drogas, e práticas diversas de violência (Alves, 1998; Aptekar, 1989; Brito, 1999; Connoly \& Ennew, 1996; Martins, 1996a, 1996b).

No estudo de crianças em situação de rua é importante apontar, também, que esse é um espaço no qual convivem a liberdade e a autonomia. $\mathrm{Na}$ ausência de um adulto cuidador que direcione suas atividades, a criança torna-se responsável por si mesma, devendo prover sua subsistência e garantir sua segurança. Estas são experiências que podem relacionar-se com o desenvolvimento de habilidades necessárias para o desenvolvimento nas ruas (Aptekar, 1989; Felsman, 1985; Koller \& Hutz, 1996; Tyler, Holliday, Echeverry, \& Zea, 1987). Tuan (1983), discutindo as características que definem um espaço, aborda as possibilidades de movimentação, a ausência de limites determinantes (espaços delimitados tornam-se lugares) e a liberdade. $\mathrm{O}$ autor ressalta que se perceber em um espaço significa estar exposto aos seus perigos e tentações, e experienciar dentro deste espaço de aprendizagem, o que "significa atuar sobre o dado e criar a partir dele" (p.10). Assim, a rua caracteriza-se como um ambiente de desenvolvimento, espaço de aprendizagem e construção de saberes. Nesse contexto encontram-se presentes valores e crenças próprios, possibilidades de subsistência e contatos sociais diver- 
sos, além da construção de uma sabedoria própria, vinculada a atitudes e pensamentos voltados para a sobrevivência (Alves, 1998; Aptekar, 1989, 1994).

O espaço da rua é dinâmico e diverso. É através do olhar atento para esse ambiente de movimentação e interação constantes que o estudo de aspectos evolutivos das crianças que nele se desenvolvem pode ser realizado. Os estudos observacionais fundamentam a possibilidade de descrição e compreensão do funcionamento deste espaço, além da identificação de comportamentos que podem ser categorizados, revelando detalhes da interação pessoa-ambiente (Alves, 1998; Pellegrini, 1996). Mais especificamente, a compreensão da dinâmica desta interação está vinculada à concepção de ser humano que tem direcionado estudos na Psicologia do Desenvolvimento. Atualmente, a Abordagem Ecológica do Desenvolvimento Humano é o referencial teórico-metodológico considerado por diversos autores como o mais adequado para estudos com populações que vivenciam situações de risco, incluindo crianças em situação de rua (Alves, 1998; Brito, 1999). Dada a diversidade presente na relação criança-rua, a visão do ser humano, enquanto determinado biopsico-histórico-socialmente, auxilia na identificação de variáveis atuantes no processo de desenvolvimento.

A Abordagem Ecológica discute o desenvolvimento humano através da interação dinâmica de quatro núcleos: Tempo, Pessoa, Processo e Contexto (Bronfenbrenner, 1979/1996, 1989, 1993; Bronfenbrenner \& Morris, 1998). O núcleo Tempo abrange questões históricas (guerras, mudanças de governo, questões de urbanização e industrialização etc.), determinações de cada fase do desenvolvimento (infância, adolescência, idade adulta e velhice), além de propostas de compreensão do processo evolutivo através de estudos longitudinais. Ainda, é importante identificar e avaliar, dentro da dimensão temporal, a freqüência e a estabilidade das atividades realizadas pela pessoa em desenvolvimento focalizada. Este procedimento viabiliza a compreensão de questões de rotina, diretamente associada à socialização. O núcleo Pessoa abrange características individuais biopsicologicamente determinadas, que atuando nas relações 
interpessoais podem ser propulsoras de desenvolvimento. Estas características podem ser identificadas como demandas (requerem uma resposta do ambiente, independentemente da manifestação de comportamentos explícitos; por exemplo: etnia, gênero, temperamento etc.), recursos (construídas no processo de socialização e que funcionam como fatores de proteção - ou risco - para o desenvolvimento; por exemplo: competência social, locus de controle etc.), e disposição (comportamentos expressos que instigam uma resposta direcionada do ambiente; por exemplo: comportamentos altruístas, birra, choro compulsivo etc.) (Bronfenbrenner \& Morris, 1998). As características da Pessoa oferecem, através de sua análise, uma chave para a compreensão dos processos de interação entre a pessoa e os ambientes que freqüenta. $\mathrm{O}$ núcleo Processo abrange as passagens e significações do desenvolvimento para cada indivíduo. Especificamente, este núcleo compreende as atividades realizadas pela pessoa em desenvolvimento com outras pessoas, com objetos e símbolos disponíveis. É importante identificar quem são os pares nas relações interpessoais, quem propõe e inicia as atividades e quais os significados atribuídos às experiências. A compreensão destes aspectos consiste, para a Abordagem Ecológica, a análise do processo de desenvolvimento em si, denominado como processo proximal. O núcleo Contexto abrange quatro níveis de interação entre quatro sistemas ecológicos: o microssistema é definido pela dimensão que possibilita a interação face-a-face entre a pessoa em desenvolvimento focalizada e os outros (também em desenvolvimento). Refere-se ao espaço de interação de diferentes personalidades, que convivem com diversos valores e crenças. A rua pode ser definida como um microssistema no contexto de desenvolvimento das crianças naquela situação. O mesossistema é definido como a interligação de diversos microssistemas, aos quais pertence a pessoa em desenvolvimento, estabelecendo relações face-a-face com outras pessoas. Os microssistemas rua, família, escola, grupos comunitários e de assistência podem integrar o mesossistema das crianças em situação de rua. O exossistema é definido como espaço de interação e convivência, no qual a pessoa em desenvolvimento focalizada não se encon- 
tra presente, mas do qual sofre influência direta da dinâmica de suas interações. Pode ser representado, neste estudo, pelas coordenações de instituições de assistência social e recreativa, grupos que tomam decisões quanto a políticas públicas, trânsito, planejamento de atividades nas ruas, praças, entre outros. O macrossistema é definido como a totalidade dos sistemas anteriores, que representam a cultura na qual está inserida a pessoa em desenvolvimento focalizada, o conjunto de crenças e valores, as regras e papéis esperados e difundidos dentro deste contexto mais amplo, além dos aspectos econômicos, sociais e históricos. No estudo de crianças em situação de rua, é relevante o conhecimento sobre o desenvolvimento econômico da cidade na qual se insere, como a sociedade vê a problemática das crianças, o preconceito que existe, e os fatos marcantes que possam ter ocorrido num espaço de tempo determinado e exercido influência na vida destas crianças (Alves, 1998; Bronfenbrenner, 1979/1996). A visão ecológica do desenvolvimento humano, também, valoriza a pesquisa em ambientes naturais e a busca de elementos saudáveis do desenvolvimento, associando-se diretamente aos objetivos de conhecimento e intervenção com populações de risco.

No modelo desenvolvido por Bronfenbrenner (1979/1996, 1989, 1993) identificam-se alguns conceitos fundamentais que sustentam estudos observacionais, entre eles as atividades molares, que ocorrem no contexto dos processos proximais. Estas atividades são definidas como "um comportamento continuado que possui um momento (quantidade, movimento, impulso) próprio e é percebido como tendo significado ou intenção pelos participantes" (Bronfenbrenner, 1979/1996, p.37). A realização destas atividades vincula-se diretamente ao crescimento físico, cognitivo e sócio-emocional dos seres humanos e pode ser descrita, muitas vezes, como atividades focais. É por meio delas, integrantes dos processos proximais, que a pessoa exercita a autonomia e o desempenho de diferentes papéis, às vezes de forma concomitante, permitindo sua atuação direta no ambiente, lidando com regras e aprendendo dentro de cada contexto específico do qual participa (Alves 1998; Bronfenbrenner, 1979/1996). Como contraponto a essas atividades, são definidas as atividades molecula- 
res, que são caracteristicamente efêmeras, não possuindo o significado e a intenção atribuídos às primeiras (Bronfenbrenner, 1979/1996).

Com base nos pressupostos teóricos abordados anteriormente, apresentam-se, em seguida, os procedimentos de construção da metodologia de observação.

\section{Construção da metodologia de observação}

Questões metodológicas e éticas foram consideradas para a construção da metodologia de observação no espaço da rua (Alves, 1998; Hutz, Koller, Forster \& Bandeira, 1995; Reppold et al., 1996). Inicialmente, foi realizado um estudo piloto com uma amostra de crianças em situação de rua, em pontos estratégicos da cidade de Porto Alegre, buscando-se parâmetros para a criação de uma metodologia própria e efetiva para a observação destas crianças. Os aspectos descritos a seguir compõem os parâmetros utilizados e as estratégias metodológicas experimentadas neste processo de criação.

\section{Permissão para a realização da observação}

Por questões éticas considerou-se a necessidade de solicitar, antes do início de cada observação, a permissão das crianças para a realização do estudo. Este procedimento, tomado a priori, resultou na observação e registro de inúmeros comportamentos estereotipados, uma vez que as crianças sabiam que estavam sendo observadas. Para a realização do estudo sobre atividades cotidianas optou-se, então, por um pedido de anuência posterior à realização da observação, reservando à criança o direito de ser retirada da amostra, caso não quisesse participar.

\section{Distância a ser mantida da criança durante a observação}

Os pesquisadores testaram diversas possibilidades de distanciamento, com o objetivo de estabelecer uma distância-padrão que viabilizasse a coleta de dados da melhor forma possível (fatores como visibilidade e possibilidade de movimentação foram considerados). Quando os observadores colocavam-se muito próximos da criança focalizada (menos de cinco metros), ficava evidente o seu 
desconforto e a mudança de atitudes frente à presença visível dos pesquisadores. A distância maior do que trinta metros possibilitava a perda de detalhes dos comportamentos e o risco de inferência nos registros, fator prejudicial para o registro da observação. Assim, um distanciamento médio de dez a trinta metros entre observador e criança, variável de acordo com a movimentação da criança, mostrouse mais apropriado.

\section{Tempo de observação}

Através de várias tentativas cronométricas, procurou-se estipular um tempo ótimo de observação, respeitando tanto o tempo de atenção contínua dos observadores, como a manifestação e manutenção dos comportamentos apresentados pelas crianças. Esse procedimento associou-se a questões, como: a diminuição das possibilidades de inferência dos comportamentos pelos observadores e com a percepção de continuidade no comportamento das crianças. Inicialmente, foi realizada uma observação com duração de uma hora. Percebeu-se, em seguida, que era um intervalo de tempo muito longo para observação, causando fadiga nos pesquisadores. Um intervalo de tempo de dez a vinte minutos revelou-se muito curto, sendo que os comportamentos registrados eram pouco representativos, frente às possibilidades de atividades no espaço da rua. Verificou-se, então, que trinta minutos poderia ser um período de observação suficiente para atender tanto aos observadores como às crianças, sendo este o tempo final estipulado para cada observação realizada no estudo.

\section{Tipo de registro}

A forma como os dados deveriam ser registrados também foi uma preocupação neste estudo. Era necessário que o instrumento utilizado fosse o mais discreto possível, e de fácil aplicação, considerando-se a dinâmica do espaço da rua. Câmaras de vídeo foram desde o início descartadas, assim como o uso de qualquer material de registro de voz (gravadores), porque chamavam muito a atenção sobre os observadores na rua. Optou-se pelo registro cursivo, realizado com papel e lápis. Inicialmente, os comportamentos observados du- 
298 P. B. Alves, S.H. Koller, A. S. Silva, C. T. Reppold, C.L. Santos, G. S. Bichinho, L. T. Prade, M. R. Silva e J. Tudge

rante trinta segundos a cada dez minutos eram registrados. No entanto, este procedimento foi abandonado em seguida, dada a dinamicidade do ambiente observado e a riqueza de comportamentos apresentados pelas crianças continuamente. Como procedimento final, definiu-se o registro cursivo de todos os comportamentos observados, sem interrupções ou janelas intervalares. No final da observação, quando a criança era abordada para que fosse pedida a permissão para se utilizar os dados, possibilitava-se o acesso aos registros realizados.

\section{A presença de dois observadores em cada observação}

Levando-se em conta o tipo de registro adotado, o tempo previsto para cada observação e a necessidade de acompanhar a criança em sua movimentação, os pesquisadores consideraram a presença de dois observadores em cada sessão como o procedimento mais adequado para a realização desta tarefa. Enquanto um observador dedicava-se a acompanhar de perto cada comportamento da criança e "ditava" o que estava vendo (da forma mais objetiva possível), o outro concentrava-se em anotar o que estava sendo dito. Este procedimento garantiu grande eficácia no registro dos comportamentos e sua posterior análise, pois cada criança foi identificada e acompanhada por dois pesquisadores e o significado dos comportamentos apresentados pode ser discutido dentro de cada situação observada.

\section{A escolha de um ponto inicial para coletar dados (starting point)}

A definição de um único ponto inicial (starting point) para a coleta de dados mostrou-se necessária, para que o horário das observações pudesse ser estipulado (era preciso saber em quais períodos do dia as crianças poderiam ser encontradas). Uma descrição ecológica do ambiente também deveria ser realizada para facilitar a compreensão das interações presentes no contexto. Optou-se pela coleta de dados em uma praça central da cidade (Praça da Alfândega), sendo esta, ponto de passagem para um grande número de crianças e de 
fácil acesso para os pesquisadores. Este espaço caracteriza-se pela presença de comércio em uma das laterais, sendo esta uma possibilidade de espaço de trabalho para as crianças, e de espaço amplo e verde na outra lateral da praça, com brinquedos infantis (trepa-trepa, balanços, tanque de areia), caracterizando espaço de brincadeira. As observações eram sempre iniciadas neste ponto e a partir daí, as crianças eram seguidas em seus diferentes percursos por trinta minutos.

\section{Horário da observação}

A presença das crianças na rua ocorre em diversos horários do dia. O local escolhido para a realização dos estudos foi visitado pelos pesquisadores em diferentes períodos e estipulou-se o horário das $10 \mathrm{~h}$ às $15 \mathrm{~h}$ como o melhor para a localização e observação das crianças. Durante este período, as crianças encontram-se em plena atividade, movimentando-se intensamente pelo local escolhido como starting point, possibilitando o aproveitamento destas condições para a coleta de dados.

\section{A escolha da criança focalizada}

Em alguns momentos (períodos de alimentação, de trabalho e de diversão), na situação de rua, é possível que sejam encontrados grupos de crianças que correspondam à descrição exigida para este estudo como crianças em situação de rua. Quando havia mais de uma criança, optava-se por um sorteio rápido, procurando-se manter uma certa aleatoriedade na composição da amostra, que já era caracteristicamente de conveniência. Uma vez que as observações foram realizadas por dois pesquisadores, um destes numerava mentalmente as crianças presentes, e o outro dizia um número, que corresponderia à criança escolhida. Este procedimento mostrou-se efetivo e evitava que a criança fosse escolhida por características, como: beleza, bom humor, extroversão ou maior atividade que as demais, fatores que poderiam comprometer os resultados de um estudo exploratório e descritivo de uma dada realidade. Para se evitar a repetição 
das crianças, um mesmo pesquisador participou de todas as identificações, antes do início de cada observação.

Considerados os oito aspectos acima descritos para a coleta de dados, a metodologia de observação de crianças em situação de rua obedeceu aos seguintes procedimentos: escolhido o starting point geográfico para o início das observações (a Praça da Alfândega), os pesquisadores estavam presentes neste local entre 10 e 15 horas, identificavam uma criança em situação de rua, entre seis e doze anos, e iniciavam o processo de observação. A criança era acompanhada por trinta minutos, a uma distância de dez a trinta metros, tendo todos seus comportamentos registrados, continuamente. Havendo mais de uma criança no starting point com as características requeridas, era feito o sorteio, estabelecendo um caráter de aleatoriedade à amostra. A composição desta metodologia de coleta de dados, com a seqüência de passos citada, possibilitou que fossem obtidos dados relativos a comportamentos que, comumente, ocorrem no contexto da rua, acentuando o caráter descritivo de uma realidade cotidiana, como salientado no objetivo geral deste trabalho.

Após o período de observação, completando o estudo descritivo, os observadores aproximavam-se da criança, apresentavam-se, falavam sobre o trabalho que estavam fazendo e pediam a permissão para a utilização dos dados. Frente à anuência da criança, ela era convidada a responder a uma entrevista bio-sócio-demográfica, que complementaria a pesquisa com informações relevantes, como, por exemplo, o local de moradia da criança, sua composição familiar e relação com escola, além da confirmação da idade (Alves, 1998; Silva et al., 1998). É importante salientar que, durante a realização deste estudo, não ocorreram negativas das crianças em participar da pesquisa.

Estruturada a metodologia de observação, o passo seguinte seria a utilização de um modelo de análise de dados coerente e consistente com os objetivos descritivos da observação. Inicialmente, considerou-se a possibilidade de uso adaptado para o contexto da rua do The cultural ecology of young children: the coding manual (Tudge, Sidden \& Putman, 1994). Originalmente, o manual desenvolvido 
por Tudge e colaboradores (1994), também baseado em princípios da Abordagem Ecológica do Desenvolvimento Humano (Bronfenbrenner, 1979/1996, 1989, 1993), foi utilizado em estudos com crianças em idade pré-escolar, em diversos países: Rússia, Coréia, Finlândia, Estônia e Estados Unidos. O manual contém descrições pormenorizadas das categorias de atividades a serem observadas e codificadas. Os autores assinalam a importância da codificação de atividades focais e não-focais, caracterizadas de acordo com a conceitualização de atividades molares e moleculares da Abordagem Ecológica, salientando sua importância com relação aos processos proximais de desenvolvimento (Bronfenbrenner, 1979/1996; Bronfenbrenner \& Morris, 1998; Tudge et al., 1999). Apesar das definições claras sobre cada tipo de atividade, nenhum comportamento deve ser descartado.

No manual de Tudge e colaboradores (1994) são apresentados cinco núcleos de atividades focais: a) Lições - envolvem atividades de aprendizagem, tanto acadêmica como de afazeres cotidianos; incluindo aqui a aquisição de habilidades específicas, conhecimento religioso, aprendizagem de comportamentos "apropriados" (pedir licença, dizer "por favor", recolocar as coisas no lugar depois de utilizá-las etc.) e preparo para a autonomia; b) Trabalho - inclui atividades de ajuda em afazeres domésticos e o engajamento em tarefas que podem, futuramente, ser importantes para a subsistência; c) Brinquedo, Exploração e Entretenimento - compreendem atividades caracterizadas pelo prazer e divertimento na sua realização, podendo envolver a aprendizagem e o aprimoramento de habilidades específicas. São incluídas nesta categoria, brincadeiras de faz de conta, com objetos acadêmicos e com brinquedos tipicamente infantis, entre outras; d) Conversação - envolve verbalizações que ocorrem durante a atividade focalizada, mas que devem ser sobre assuntos diversos da atividade focal; e, e) Outras - incluem atividades moleculares de cuidados básicos, como dormir, ir ao banheiro, comer etc. Deve, ainda, existir o registro das interações mantidas pela criança focalizada, em que aspectos como quem é o parceiro na interação, quem a inicia e qual o papel desempenhado tanto pela criança como por seu 
parceiro, são fundamentais. A categorização dos dados é realizada durante as sessões de observação, através do preenchimento de uma folha de registro previamente estruturada. Há a necessidade de treinamento prévio dos observadores, para que a coleta de dados seja padronizada e haja um mínimo de inferência nos comportamentos observados. Esta capacitação é, normalmente, realizada através da análise de vídeotapes.

Frente a toda a especificidade contextual da rua e os parâmetros traçados através do estudo piloto realizado com crianças nesse ambiente, permitiu-se concluir que, mais do que uma adaptação do material proposto por Tudge e colaboradores (1994), era necessária a criação de um manual de codificação específico para a situação de rua. Algumas dificuldades, como o acompanhamento de verbalizações e da movimentação em um espaço muito amplo, deveriam ser consideradas. Ainda, as crianças estudadas nesta situação eram geralmente mais velhas do que as estudadas por Tudge e colaboradores (1994), variando entre seis e doze anos de idade, vivendo um quadro evolutivo diferenciado devido à combinação, constantemente presente, entre aspectos saudáveis do desenvolvimento e fatores de risco no espaço da rua.

Como os registros das observações em situação de rua foram realizados de maneira cursiva, a criação do manual para análise destes dados deveria ser feita através da leitura sucessiva dos dados, com a teoria adotada servindo como "pano de fundo" para possíveis interpretações dos resultados. Assim, buscou-se um modelo de análise que privilegiasse todos os dados coletados, utilizando-se o manual de Tudge e colaboradores (1994) como parâmetro para a discussão de algumas categorias semelhantes entre este trabalho e o desenvolvido com crianças em situação de rua, como brinquedo, trabalho e contatos sociais.

Os registros de todas as observações realizadas na situação de rua foram lidos pelo grupo de pesquisa e elegeu-se o modelo quantitativo-interpretativo (Biasoli-Alves, 1988) como o mais adequado para sua análise. Neste modelo, estruturado para analisar tanto dados de observação como de entrevistas, seguem-se os seguintes passos: 
a) Investigação: momento no qual investiga-se cada comportamento ou resposta apresentada, classificando-os segundo a proximidade de sentido que apresentam. Este procedimento permite um agrupamento inicial dos dados. Nesta etapa, objetiva-se compreender o significado e a importância do dado coletado para os objetivos do estudo, além de analisar a relevância e a adequação do instrumento utilizado, frente aos resultados obtidos. As críticas metodológicas e as sugestões de refinamento na composição e aplicação de instrumentos fundamentam-se nesta etapa da análise, que pode estar associada à realização de estudos-piloto.

b) Categorização: momento no qual, através de um estudo minucioso de cada comportamento ou fala dos participantes, criam-se agrupamentos válidos dos dados. Os critérios utilizados para a criação destes agrupamentos (categorias) são: exaustividade (análise de todas as formas de respostas obtidas), exclusividade (cada categoria classifica um grupo de respostas) e manutenção (as categorias devem ter um mesmo nível de inferência e interpretação das respostas, evitando-se grandes oscilações no contínuo objetividade-subjetividade (Alves, 1998; Biasoli-Alves, 1988).

Após este procedimento inicial de análise, foi estruturado o Manual de codificação de atividades cotidianas de crianças em situação de rua (Alves, Koller \& Tudge, 1996) e criada uma folha de registro para que os dados coletados de forma cursiva pudessem ser transformados, posteriormente, em códigos, facilitando sua análise (Alves, 1998). O manual é composto pela definição de quatro grandes categorias de atividades: 1) Trabalho; 2) Brinquedo, Exploração e Entretenimento; 3 ) Observações de Contexto; e, 4) Outras. Também, considerou-se o papel desempenhado pela criança focalizada na atividade observada (direção, esquiva, facilitação, participação, observação e espreita), a identificação do parceiro de interação ou contato social (adulto, adolescente ou criança), o nível de interação ou contato estabelecido (conversa, brinquedo, trabalho, contato físico e cuidado) e possíveis expressões faciais (sorriso, choro e braveza). Todas as categorias aqui citadas possuem definiçõos explícitas e subdivisões, privilegiando a análise do maior número possível de comportamentos observados (para maiores detalhes, ver Alves, 1998). 
304 P. B. Alves, S.H. Koller, A. S. Silva, C. T. Reppold, C.L. Santos, G. S. Bichinho, L. T. Prade, M. R. Silva e J. Tudge

\section{Discussão}

O estudo observacional de crianças em situação de rua e a análise de dados através do manual aqui apresentado têm trazido importantes reflexões, tanto teóricas como metodológicas. Inicialmente, é necessário valorizar os estudos observacionais, em ambiente natural, de caráter exploratório e descritivo (Pellegrini, 1996). É através da análise dos resultados apresentados que realidades podem ser conhecidas e, muitas vezes, modificadas para melhor. Sabe-se que no caso de projetos e planos de intervenção em situações de risco, a inferência pode ser mais um risco associado aos demais. É preciso conhecer o contexto, procurar o sentido da relação pessoa-ambiente que nele ocorre, identificar variáveis que podem interferir nesse processo, enfim, observar, registrar e analisar as situações. Não se desmerecem, aqui, estudos nos quais se privilegie a fala dos participantes através da realização de entrevistas. Apenas, salienta-se a necessidade da utilização de métodos adequados para cada situação e para cada problema de pesquisa, que, em muitos casos, podem e devem ser diferentes e complementares.

Um outro ponto a ser considerado relaciona-se às teorias de desenvolvimento clássicas e à percepção do processo evolutivo dentro de situações de risco. Não é possível, sem dados de pesquisa evidentes, classificar as situações estressoras como paralisantes ou interruptoras do desenvolvimento. Deve-se, sim, identificá-las como situações especiais e delicadas, que necessitam de atenção e cuidado, mas sem desconsiderar o potencial de adaptação e busca de saúde inerente ao ser humano. Observar crianças em situação de rua e suas atividades cotidianas é um exemplo claro do que foi colocado acima. No manual, criado para analisar os dados, podem ser identificados inúmeros comportamentos saudáveis e adequados para a faixa etária estudada, como o brinquedo, a convivência com pares e com outras pessoas de idades diferentes, além da movimentação constante por espaços amplos e estimulantes. É preciso, dentro da Psicologia do Desenvolvimento, procurar concepções contemporâneas do ser humano, que valorizem aspectos globais, como cultura, história, gené- 
tica, processos psicológicos e, principalmente, a dinâmica de interação existente entre eles.

Na metodologia aqui descrita, realizada com base na Abordagem Ecológica do Desenvolvimento Humano (Bronfenbrenner, 1979/ 1996, 1989, 1993), a ênfase está na discussão dos elementos do Contexto, principalmente pela relação existente com a ocorrência dos processos proximais. Este enfoque teórico-metodológico permite o reconhecimento da rua enquanto um ambiente de desenvolvimento, onde os aspectos de saúde podem ser identificados e reforçados. Enquanto um microssistema, a rua comporta relações interpessoais que valorizam o afeto, a reciprocidade e o equilíbrio de poder (Alves, 1998). A utilização do manual permite a identificação destes contatos sociais e seus sentidos mais gerais, como o brinquedo, o trabalho e as interações verbais. Ainda, estar na rua pode caracterizar a oportunidade de vivência de diferentes papéis sociais (a criança, o trabalhador, o cuidador de outras crianças, o companheiro nas brincadeiras), que acrescentam experiências e aprendizagens na vida da criança, além de promover sua autonomia. Também as experiências mais aversivas, como o confronto com a polícia, a reação de desgosto e preconceito das pessoas que transitam pelas ruas, o risco do uso de drogas, entre outras, são experiências que impõem a necessidade de criação de estratégias para sobrevivência e desempenho de papéis. Mesmo que esses comportamentos não tenham sido identificados durante o estudo que resultou na composição do manual, eles são relevantes para o estudo de processos de desenvolvimento proximais.

A identificação dos elementos do mesossistema destas crianças (a presença da família, da escola, da comunidade) permite que o quadro traçado, através da observação, se amplie, acrescentando dados importantes nas discussões, que envolvem projetos de intervenção remediativos e preventivos junto a esta população. $\mathrm{O}$ mesmo pode ser dito com relação ao conhecimento e análise dos aspectos sócio-culturais do exossistema e macrossistema (Alves, 1998; Brito, 1999).

Por fim, trabalhar com o conceito de atividades molares, observação naturalística e crianças em situação de rua é criar uma ponte 
importante entre aspectos teóricos da Psicologia do Desenvolvimento e realidades sociais diferenciadas. A utilização do Manual de codificação de atividades cotidianas de crianças em situação de rua (Alves et al., 1996) favorece o diálogo entre pesquisadores que trabalham com esta população, subsidiando novos estudos na área. O objetivo final deve ser a aplicação direta dos conhecimentos produzidos mediante a pesquisa, visando, principalmente, à promoção de saúde integral de crianças e adolescentes.

\section{Referências}

Alves, P. B., Koller, S. H., \& Tudge, J. (1996). Manual de codificação de atividades cotidianas de crianças em situação de rua. Manuscrito nãopublicado. Curso de Pós-Graduação em Psicologia do Desenvolvimento, Universidade Federal do Rio Grande do Sul, Porto Alegre, RS.

Alves, P. B. (1998). O brinquedo e as atividades cotidianas de crianças em situação de rua. Dissertação de mestrado não-publicada, Curso de PósGraduação em Psicologia do Desenvolvimento, Universidade Federal do Rio Grande do Sul, Porto Alegre, RS.

Aptekar, L. (1989). Characteristics of street children of Colômbia. Child Abuse and Neglect, 133, 427-437.

Aptekar, L. (1994). Street children in the developing world: A review of their condition. Cross Cultural Research, 28, 195-224.

Bemak, F. (1996). Street researchs: A new paradigm redefining future research with street children. Childhood, 3, 147-156.

Biasoli-Alves, Z. M. M. (1988). Intersecções das abordagens qualitativas e quantitativas. In D. G. Souza, V. R. Otero, \& Z. M. M. Biasoli-Alves (Orgs.), Anais da $18^{a}$ Reunião Anual de Psicologia da Sociedade de Psicologia de Ribeirão Preto (pp. 487-489). Ribeirão Preto: SBP.

Biasoli-Alves, Z. M. M. (1992). Discutindo o desenvolvimento infantil e dos adolescentes. Cadernos de Terapia Ocupacional, 3, 1-37.

Brito, R. C. (1999). Uso de drogas entre meninos e meninas de rua: subsídios para uma intervenção comunitária. Dissertação de mestrado nãopublicada, Curso de Pós-Graduação em Psicologia do Desenvolvimento, Universidade Federal do Rio Grande do Sul, Porto Alegre, RS.

Bronfenbrenner, U. (1989). Ecological systems theory. Annals of Child Development, 6, 187-249.

Bronfenbrenner, U. (1993). The ecology of cognitive development: Research models and fugitive findings. In R. Wozniak \& K. Fischer (Orgs.), Development in context: acting and thinking in specific environments (pp. 3-44). Hillsdale, New Jersey: Erlbaum. 
Bronfenbrenner, U. (1996). A ecologia do desenvolvimento humano: Experimentos naturais e planejados. Porto Alegre: Artes Médicas. (Originalmente publicado em 1979)

Bronfenbrenner, U., \& Morris, P. (1998). The ecology of developmental processes. In R. M. Lerner (Org. Volume) \& W. Damon (Org. Série), Handbook of child psychology: Theoretical models of human development (Vol. 1, pp. 993-1027). New York: Wiley .

Connoly, M., \& Ennew, J. (1996). Introduction. Children out of place. Childhood, 3, 131-145.

Felsman, J. K. (1985, December). Street children: a selected bibliography. Educational Resources Information Center, pp. 2-21.

Forster, L. M. K., Barros, H. M. T., Tannhauser, S. L., \& Tannhauser, M. (1992). Meninos na rua: Relação entre abuso de drogas e atividades ilícitas. Revista da ABP-APAL, 14, 115-120.

Hawkins, P. (1986). Children at risk: my fight against child abuse: a personal story and public plea. Bethesda: Adler \& Adler.

Hutz, C. S., Koller, S. H., Forster, L. M., \& Bandeira, D. R. (1995, Julho). Ethical issues in research with street children. Simpósio apresentado no Interamerican Congress of Psychology, San Juan, Puerto Rico.

Hutz, C. S., \& Koller, S. H. (1997). Questões sobre o desenvolvimento de crianças em situação de rua. Estudos de Psicologia, 2, 175-197.

Hutz C. S., \& Koller, S. H. (1999). Methodological and ethical issues in research with street children. New Directions for Child Development, 86, 240-268.

Koller, S. H., \& Hutz, C. S. (1996). Meninos e meninas em situação de rua: dinâmica, diversidade e definição. Coletâneas da ANPEPP, 1, 5-12.

Martins, R. A. (1996a). Censo de crianças e adolescentes em situação de rua em São José do Rio Preto. Psicologia: Reflexão e Crítica, 9, 101122.

Martins, R. A. (1996b). Crianças e adolescentes em situação de rua: definições, evolução e políticas de atendimento. Coletâneas da ANPEPP, 1 , 35-44.

Masten, A. S., \& Garmezy, N. (1985). Risk, vulnerability, and proctetive factors in developmental psychopathology. In B. B. Lahey \& A. E. Kazdin (Orgs.), Advances in clinical child psychology (Vol.8, pp. 1-52). New York: Plenum.

Pellegrini, A. D. (1996). Observing children in their natural worlds. A methodological primer. New Jersey: Erlbaum.

Reppold, C., Santos, C. L., Silva, A. S., Silva M. R., Alves, P. B., \& Koller, S. H. (1996). O cotidiano e a rua: Atividades de crianças em situação de rua na cidade de Porto Alegre [Resumo]. In Sociedade Brasileira de 
Psicologia (Org.), Resumos de comunicação científica, XXVI Reunião Anual de Psicologia (pp.94-95). Ribeirão Preto: SBP.

Rutter, M. (1985). Resilience in face of adversity: protective factors and resience to psychiatric disorder. British Journal of Psychiatric, 147, 598-611.

Rutter, M. (1987). Psychosocial resiliense and protective mechanisms. American Journal of Orthopsychiatry, 57, 316-331.

Silva, A. S., Reppold, C. T., Santos, C. L., Prade, L. T., Silva, M. R., Alves, P. B., \& Koller, S. H. (1998). Crianças em situação de rua de Porto Alegre: um estudo descritivo. Psicologia: Reflexão e Crítica, 11, 555582.

Tuan, Yi-Fu (1983). Espaço e lugar: A perspectiva da experiência. São Paulo: Difel.

Tudge, J., Sidden, J., \& Putnam, S. (1994). The cultural ecology of young children: Coding manual. Manuscrito não-publicado. University of North Carolina, Greensboro, EUA.

Tudge, J., Doucet, F., Odero, D., Tammeveski, P., Lee, S., Meltsas, M., \& Kulakova, N. (1999). Desenvolvimento infantil em contexto cultural: o impacto do engajamento de pré-escolares em atividades do cotidiano familiar. Interfaces, 2, 23-32.

Tyler, F. B., Holliday, M. Y., Tyler, S. L., Echeverry, J. J., \& Zea, M. C. (1987). Street children and play. Children's Environment Quarterly, 4, 13-17.

Paola Biasoli Alves, psicóloga, mestre em Psicologia do Desenvolvimento, aluna do Curso de
Nota ${ }^{1}$ Este trabalho é parte da Dissertação de Mestrado da primeira autora, sob orientação da Prof ${ }^{a} \mathrm{Dr}^{\mathrm{a}}$ Sílvia H. Koller, no Programa de Pós-Graduação em Psicologia do Desenvolvimento da Universidade Federal do Rio Grande do Sul, Porto Alegre, RS. Apoio CAPES.

Sobre os autores 
Doutorado na mesma área, do Instituto de Psicologia da Universidade Federal do Rio Grande do Sul e bolsista da CAPES, é membro do CEP-RUA e co-coordena o Núcleo de Estudos e Capacitação em Desenvolvimento Humano (NECADEH) e o Programa de Capacitação em Sexualidade, AIDS e Drogas (PISAD) pertencentes ao CEP-RUA do Instituto de Psicologia/UFRGS.

Silvia Helena Koller, psicóloga, doutora em Educação pela Pontifícia Universidade Católica do Rio Grande do Sul/Arizona State University (EUA), Pesquisadora do CNPq, Coordenadora do Centro de Estudos Psicológicos sobre Meninos e Meninas de Rua (CEP-RUA), é professora e orientadora nos Cursos de Graduação e Pós-Graduação em Psicologia do Desenvolvimento da Universidade Federal do Rio Grande do Sul.

Aline S. Silva, Caroline T. Reppold, Clarisse L. Santos, Gabriela S. Bichinho, Luciano T. Prade e Milena R. Silva são estudantes do Curso de Graduação em Psicologia da Universidade Federal do Rio Grande do Sul, membros do CEP-RUA e bolsistas de Iniciação Científica (PET/CAPES, CNPq, $\quad \mathrm{PIBIC/CNPq} \mathrm{e}$ FAPERGS).

Jonathan Tudge (coorientador deste trabalho), Ph.D. em Psicologia do Desenvolvimento pela University of Cornell, Ithaca, NY (EUA), é pesquisador 
310 P. B. Alves, S.H. Koller, A. S. Silva, C. T. Reppold, C.L. Santos, G. S. Bichinho, L. T. Prade, M. R. Silva e J. Tudge

e professor na University of North Carolina at Greensboro (EUA).

Endereço para correspondência: CEP-RUA, Instituto de Psicologia, Universidade Federal do Rio Grande do Sul. Rua Ramiro Barcelos, 2600, sala 104, 90035-003, Porto Alegre, RS.

Fone: (51) 316.5150 Fax: (51) 330.4797

E-mail:paolabia@yahoo.com. 